\title{
Increasing trend in Type 1 (insulin-dependent) diabetes mellitus in childhood in Finland
}

\author{
Analysis of age, calendar time and birth cohort effects during 1965 to 1984 \\ J. Tuomilehto ${ }^{1}$, M. Rewers ${ }^{2}$, A. Reunanen ${ }^{3}$, P. Lounamaa ${ }^{1}$, R. Lounamaa ${ }^{1}$, E.Tuomilehto-Wolf ${ }^{1}$ and H. K. Åkerblom ${ }^{4}$ \\ Department of Epidemiology, National Public Health Institute, Helsinki, Finland, \\ 2 Academy of Medicine, Poznan, Poland, \\ ${ }^{3}$ Social Insurance Institution, The Research Institute for Social Security, Helsinki, \\ 4 The Children's Hospital, 2nd Department of Paediatrics, University of Helsinki, Helsinki, Finland
}

Summary. The Central Drug Registry in Finland ascertained 5,920 incident cases of Type 1 (insulin-dependent) diabetes mellitus diagnosed under the age of 15 years, during 1965-1984. The incidence was higher for males $29.2 / 100,000$ (95\% confidence intervals $28.2-30.2 / 100,000)$ than for females 26.1/100,000 (25.1-27.1/100,000). A non-linear increase in incidence with age was confirmed, with peaks at ages 2,9 and 14 years in males and at 3,5-6 and 11 years in females. A significant temporal variation in incidence was found, adjusting for age and sex. During 1965 to 1984 the incidence rose by about $57 \%$ or by $2.4 \%$ annually. However, a non-linear curve with two incidence peaks in 1978 and 1983 would better describe the temporal pattern than a linear trend. There was no significant difference in the temporal variation between males and females. The changes in diabetes risk appeared to affect proportionally all age groups under 15 years. Two possible mechanisms were explored: a calendar period effect vs a birth cohort effect. The calendar time period effect was significant alone and also when adjusted for the birth cohort effect. One the contrary, the birth cohort effect was not significant, when adjusted for the calendar period effect. In conclusion, over the past two decades, the incidence of childhood Type 1 diabetes in Finland has increased by about $57 \%$. The pattern of change was a steady rising background incidence superimposed by sudden outbreaks suggesting environmental causative factors.

Key words: Type 1 diabetes, incidence, epidemiology, time trends, Finland.
The adoption of standard epidemiological methods and criteria for Type 1 (insulin-dependent) diabetes mellitus in epidemiologic studies [1], has made it possible to study the variation in the incidence of Type 1 diabetes. Such research has largely focussed on geographic variation [1-4]. In some populations also temporal variation in the incidence has been assessed, but either the observation period was short, or the number of cases diagnosed during each calendar year too small for a reliable trend assessment [5-11].

There are three distinct sources that may result in a change in the incidence $[12,13]$ :

1. period effect, i.e. a change with time across all age groups,

2. age effect, i. e. a change in age relation of the disease risk and

3. cohort effect, i.e. sustained differences in the risk among different birth cohorts.

Age-period-birth cohort techniques are increasingly used in the evaluation of disease trends, particularly cancer [12,
$13,15]$ and substance abuse [16]. Recently, these techniques have also been applied to incidence data of Type 1 diabetes [10,11]. Earlier data have demonstrated a marked increase in the incidence of Type 1 diabetes in Finnish children during the past decades $[16,17]$ in the country where the incidence is the highest in the world $[3,4]$.

The purpose of this paper is to describe the 20-year trend in the incidence of Type 1 diabetes in Finland and to determine which of the three potential effects account mainly for the variation in the incidence.

\section{Subjects and methods}

Case definition of childhood Type 1 diabetes

Cases were selected for inclusion into the present analysis if they fulfilled the following standard case definition criteria for childhood Type 1 diabetes: 1.) Diagnosed as being diabetic. 2.) Placed on insulin therapy before the 15 th birthday. 3 .) Resident in Finland at the time of the first administration of insulin. 
Table 1. Mean annual incidence (per 100,000), number of cases $(n)$ and the $95 \%$ confidence interval (C.I.) for the mean incidence of Type 1 (insulin-dependent) diabetes in Finland in children aged less than 15 years at diagnosis during 1965 to 1984

\begin{tabular}{|c|c|c|c|c|}
\hline & \multicolumn{3}{|c|}{ Age group (years) } & \multirow{2}{*}{$\begin{array}{l}\text { Age-adjusted } \\
0-14\end{array}$} \\
\hline & $0-4$ & $5-9$ & $10-14$ & \\
\hline $\begin{array}{l}\text { Males } \\
\text { incidence } \\
(n) \\
95 \% \text { C.I. }\end{array}$ & $\begin{array}{l}18.6 \\
(662) \\
17.2-20.1\end{array}$ & $\begin{array}{l}30.2 \\
(1,087) \\
28.5-32.0\end{array}$ & $\begin{array}{l}38.0 \\
(1,469) \\
36.1-40.0\end{array}$ & $\begin{array}{l}29.2 \\
(3,178) \\
28.2-30.2\end{array}$ \\
\hline $\begin{array}{l}\text { Females } \\
\text { incidence } \\
(n) \\
95 \% \text { C. I. }\end{array}$ & $\begin{array}{l}16.6 \\
(532) \\
15.2-18.1\end{array}$ & $\begin{array}{l}29.4 \\
(1,013) \\
27.5-31.2\end{array}$ & $\begin{array}{l}32.2 \\
(1,197) \\
30.4-34.1\end{array}$ & $\begin{array}{l}26.1 \\
(2,742) \\
25.1-27.1\end{array}$ \\
\hline $\begin{array}{l}\text { Total } \\
\text { incidence } \\
(n) \\
95 \% \text { C.I. }\end{array}$ & $\begin{array}{l}17.6 \\
(1,154) \\
17.2-20.1\end{array}$ & $\begin{array}{l}29.8 \\
(2,100) \\
28.5-31.1\end{array}$ & $\begin{array}{l}35.1 \\
(2,666) \\
33.8-36.5\end{array}$ & $\begin{array}{l}27.6 \\
(5,920) \\
26.9-28.3\end{array}$ \\
\hline
\end{tabular}

\section{Case ascertainment}

Since 1965 drug treatment for diabetes has been free-of-charge in Finland. Patients have received reimbursement from the Social Insurance Institution after the Institution has received an application based on a certificate from the doctor treating the patient. Only occasionally does a diabetic child or adolescent not seek reimbursement for insulin costs and is thus not included in the nationwide Central Drug Registry. The ascertainment rate of childhood Type 1 diabetes in Finland is therefore almost $100 \%$.

The Central Drug Registry only recorded the date of approval of the free-of-charge medication. During the 1960's and early 1970's the difference between the date of diagnosis and the approval of free medication could be large. For our present analysis the actual date of diagnosis for each subject was required. Therefore, we collected copies of the original certificates for the years 1965-1979 from the local offices of the Social Insurance Institution in 1987. A few cases which did not fulfill the criteria for Type 1 diabetes were excluded. For the years 1980-1984 the reports of the Central Drug Registry were adopted without checking the original certificates, because our validation showed that the dates in the Central Drug Registry were adequate since the late 1970 's. The number of cases aged less than 15 years at diagnosis and diagnosed during 1965 to 1984 was 5,920 (3,178 males and 2,742 females). The birth cohorts included were from 1950 to 1983 .

\section{Population at risk}

Population data were obtained from the Social Insurance Institution. The denominator data were available by sex, calendar year and by 5-year age groups for the years 1965-1975, and by each year of age for the years 1976-1984.

For the period 1965-1975 the estimated population denominators by each year of age were obtained through a cohort-wise, margin-adjusted interpolation [18] of the population data available for 5 -year age groups.

\section{Statistical analysis}

The direct age-standardization [19] assumed the standard population for both sexes to be distributed as follows: age-group 0-4 years, $33 \%$; age-group 5-9 years, 33\%; age-group $10-14$ years, $34 \%$ according to the previous comparative studies for childhood Type 1 diabetes $[2,3]$.

Poisson regression models were fitted to the annual incidence data using maximum likelihood estimation in the statistical package
GLIM [20]. The risk of developing Type 1 diabetes under the age of 15 years was modelled as a function of age, sex, calendar year (period), birth cohort, and interactions between these factors. To break the exact linear dependency between the age, period, and cohort indices, which creates the identifiability problem, the annual age and period categories were used and birth cohorts were grouped into 20 categories. Patient's birth cohort was calculated as follows:

birth cohort $=$ year of diagnosis $-($ age +1$)$

The seven extreme birth cohort categories (1950-1954, 1955-1956, 1957-1958 and 1972-1973, 1974-1975, 1976-1978, 1979-1983) consisted of more than one calendar year cohort. Thirteen central cohort categories theoretically covered one year, with a maximal overlap of one year on both sides. This technique of birth cohort categorization was used to assure a balance in the degree of adjustment for cohort effect vs calendar period effect and has been discussed in more detail elsewhere [10].

The significance of the main effects and their interactions was assessed using likelihood ratio statistics, and a forward stepwise approach was used to select the significant predictors. The number of incident cases (Y) in a particular group during a particular period was assumed to have a Poisson distribution with a mean $(\mathrm{Nr})$, where $(\mathrm{N})$ is the population at risk in that group and (r) is the risk of developing diabetes during that period. The risk $(r)$ is modelled as a multiplicative function of the explanatory variables, or equivalently, the logarithm of the risk can be modelled as an additive function of the predictors [20].

Obtained 'deviance' is a measure of the discrepancy between the observed and fitted values in generalized linear models (21). The baseline was females in the youngest age category in 1965 . No adjustment was made for multiple comparisons.

\section{Results}

\section{Descriptive analysis}

During 1965 to 1984 , the mean annual incidence of Type 1 diabetes in Finnish males, 29.2/100,000 (95\% confidence intervals [CI] 28.2-30.2), was significantly higher than in females, 26.1/100,000 (CI 25.1-27.1) (Table 1). The age distribution of the incidence is shown in Figure 1. The increase in incidence with age was non-linear.

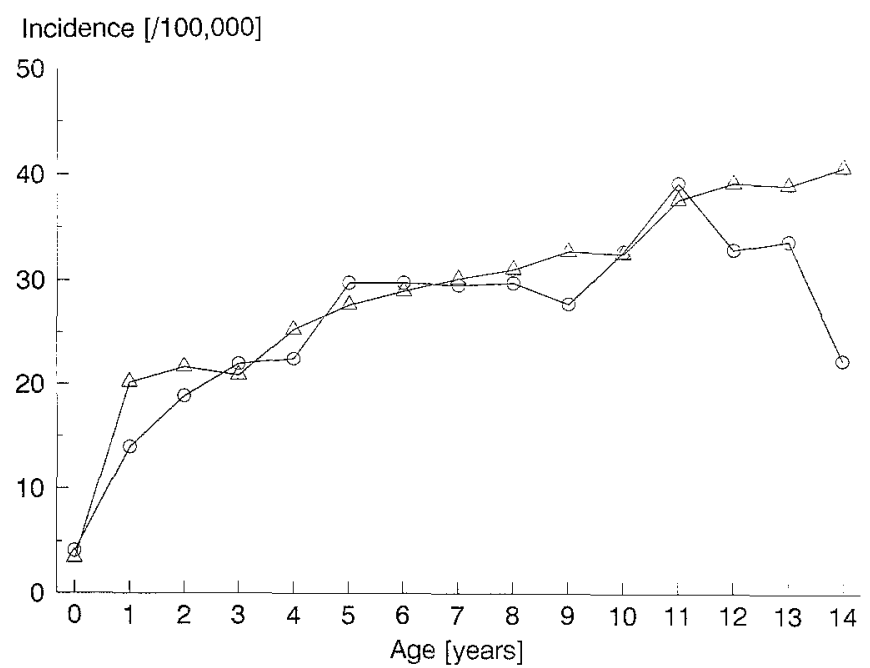

Fig.1. Average annual incidence of Type 1 (insulin-dependent) diabetes per 100,000 in Finnish males and females aged less than 15 years at diagnosis by age. Incidence data for the years from 1965 to 1984 are pooled together. $\triangle$ male subjects, $O$ female subjects 


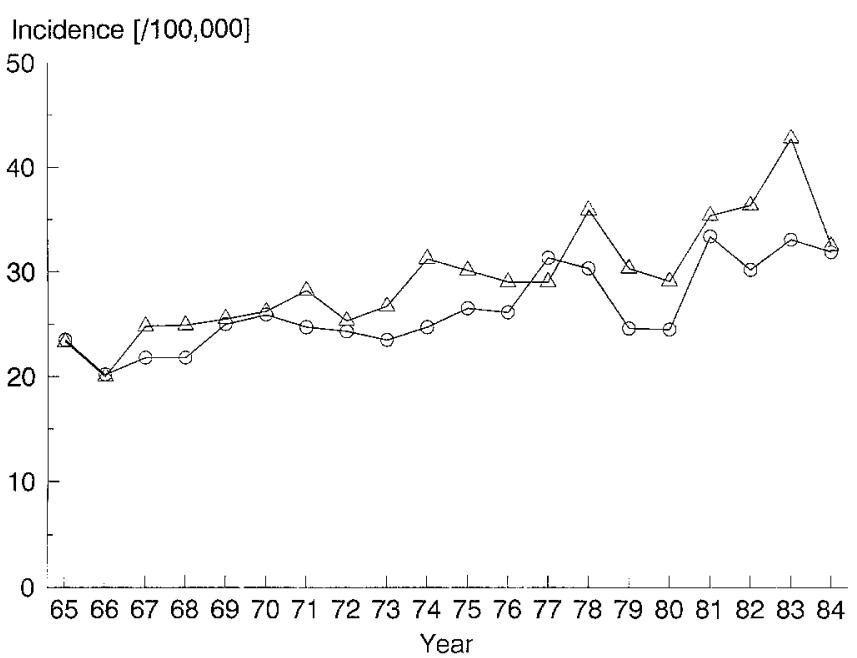

Fig. 2. Age-adjusted annual incidence of Type 1 (insulin-dependent) diabetes per 100,000 in Finnish males and females aged less than 15 years at diagnosis during 1965 to 1984 . $\triangle$ male subjects, O female subjects

The age-adjusted annual incidence (males and females together) varied markedly over time. It was lowest in $1966(20.4 / 100,000)$ and highest in $1983(38.0 / 100,000)$. For exploratory analysis of the temporal variation in the incidence of Type 1 diabetes, sex-specific age-adjusted rates (Fig. 2), and age specific rates separately for males and females in the three age-groups (Fig. 3) were plotted.

There were some differences in the variation in incidence between males and females although not statistically significant. The $1982-1983$ peak was not clearly present in females. The increase in the age-adjusted incidence from $1965-1967$ to $1982-1984$ was $64 \%$ in males and $48 \%$ in females. The age group specific changes in the incidence were $103 \%, 74 \%$ and $32 \%$ in males and $34 \%$, $71 \%$ and $37 \%$ in females aged $0-4$ years, $5-9$ years and 10-14 years, respectively. There was an overall parallelism of the age-specific time curves in both sexes (Fig. 3). In females, however, the incidence for these two oldest 5-year age groups came somewhat closer in 1973 and remained nearly the same since that time.

\section{Regression modelling}

Table 2 describes the overall results from the regression modelling of the risk of Type 1 diabetes. Age was the strongest predictor of the risk (model 2$)$. Both sex (model 3) and interaction of age and sex (model 4) were also significant. Therefore, the evaluation of the temporal variation in incidence, was done after adjusting for the effects of age and sex. There was a statistically significant $(p<0.001)$ temporal variability (model 5$)$, also evident from inspection of Figure 2.

To assess whether this temporal pattern could adequately be described as a linear trend, the categorical period variable was replaced by a linear term for period (with one degree of freedom). The resulting model (model 6) fitted the data significantly worse than the non-linear model (model 5). However, most of the increase in incidence was explained by a linear trend. According to the regression model the overall age-adjusted incidence (males and females together) rose by about $57 \%$ or by $2.4 \%$ annually (beta $=0.024$ for trend) between 1965 and 1984.

An interaction term period*sex was added to model 5, but no significant difference in the time trend between the sexes was found (model 7).

A possible interaction of calendar time period with age was formally tested in model 8 where age was grouped into three 5-year categories. There was no evidence for differences in the increase in the incidence by age, i.e. the relative increase with time was practically the same across all ages.

Finally, we tested whether birth cohort effect could better explain the observed change in the incidence than the calendar period effect. The birth cohort effect was not statistically significant over and above the calendar time period effect (model 9). On the contrary, the calendar time period still remained significant, after the adjustment for the birth cohort effects, as demonstrated by worsening of the fit when the calendar time period effect was dropped from the model (model 10).

The trend predicted from model 5 was plotted and compared to the crude observed rates (Fig. 4). No simple
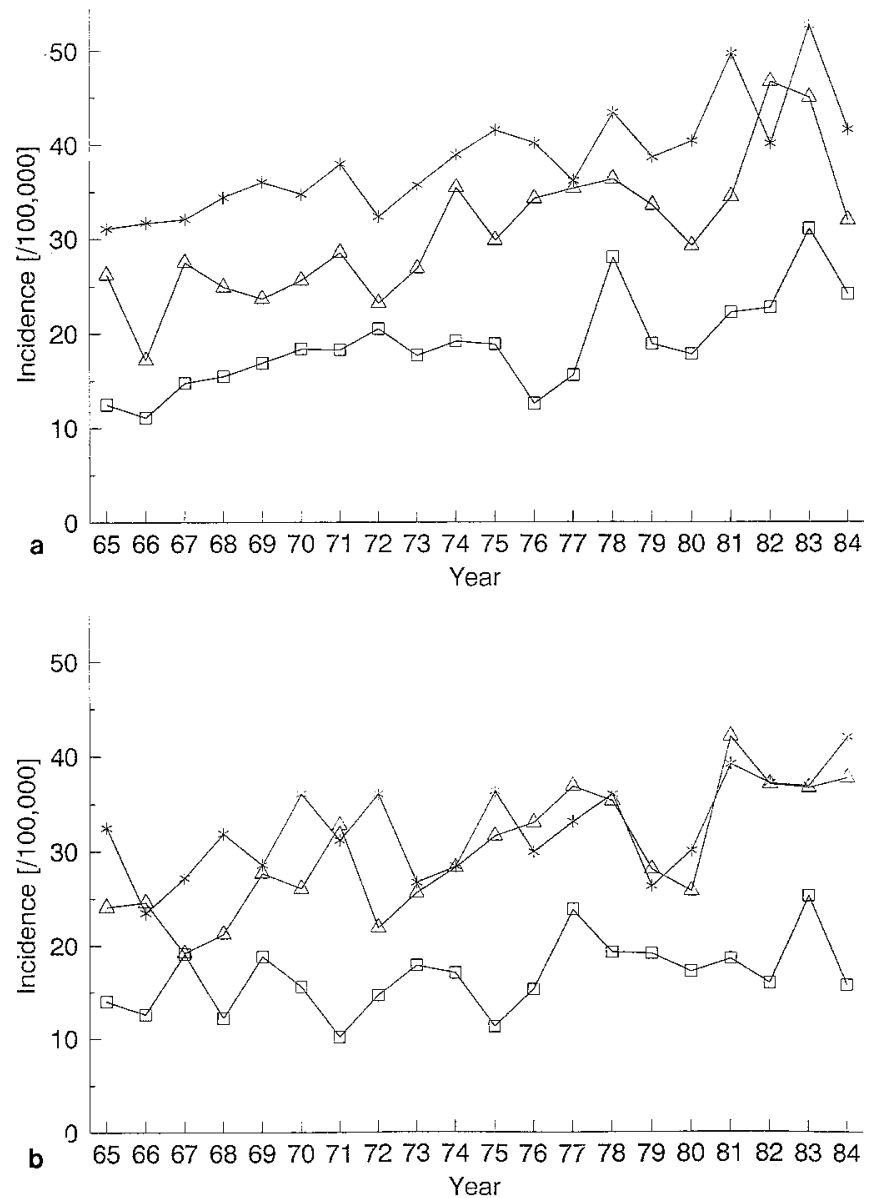

Fig.3a, b. Age-specific annual incidence of Type 1 (insulin-dependent) diabetes per 100,000 in Finnish males (a) and females (b) aged less than 15 years at diagnosis during 1965 to 1984 by age. Age groups are the following: $\square 0-4$ years, $\triangle 5-9$ years, $* 10-14$ years 
Table 2. The selection of variables in age, calendar time period and birth cohort models of the risk of Type 1 (insulin-dependent) diabetes in Finnish children aged less than 15 years at diagnosis during $1965-1984$. The likelihood ratio statistic (LRS), degrees of freedom (df) and the $p$-value correspond to the term last entered or removed

\begin{tabular}{|c|c|c|c|c|c|}
\hline \multirow[t]{2}{*}{ Model } & \multicolumn{2}{|c|}{ Model } & \multicolumn{3}{|c|}{ Last term } \\
\hline & $\mathrm{df}$ & Deviance & LRS & df & $p$-value \\
\hline 1. constant & 599 & $1,489.2$ & & & \\
\hline 2. c, age & 585 & 813.2 & 676.0 & (14) & $<0.001$ \\
\hline 3. c, age, sex & 584 & 796.4 & 16.8 & $(1)$ & $<0.001$ \\
\hline 4. c, age, sex, age $*$ sex & 570 & 749.2 & 47.2 & (14) & $<0.001$ \\
\hline 5. c, age, sex, age*sex, period & 551 & 605.7 & 143.5 & (19) & $<0.001$ \\
\hline 6. c, age, sex, age sex, trend & 569 & 636.0 & 30.1 & (18) & $<0.05$ \\
\hline 7. c, age, sex, age*sex, period, period*sex & 532 & 593.7 & 12.0 & (19) & NS \\
\hline 8. c, age, sex, age*sex, period, period ${ }^{*}$ age 3 & 513 & 569.8 & 35.9 & (38) & NS \\
\hline 9. c, age, sex, age*sex, period, cohort & 532 & 584.0 & 21.7 & (19) & NS \\
\hline 10. c, age, sex, age*sex, cohort & 551 & 615.6 & 31.6 & (19) & $<0.05$ \\
\hline
\end{tabular}

$C$ denotes constant. Period and cohort stand for, respectively, calendar year and birth cohorts categorized into 20 groups (Table 1). Trend represents a linear term for the calendar year effect. Age 3 denotes the age variable categorized into three groups $0-4,5-9$, and 10-14 years curvilinear function could be suggested from the plot. Using Wald's statistic [20], it can be estimated that the incidence during 1974-1978 and 1981-1984 was significantly higher than baseline.

\section{Discussion}

The present data from Finland covering the 20-year period 1965-1984 demonstrated a marked increase of about $60 \%$ or $2.4 \%$ per year in the incidence of Type 1 diabetes in Finnish children during the 20-year period 1965-1984. The incidence of childhood Type 1 diabetes in Finland increased continuously, but in a non-linear manner. The trend was similar in both sexes and in the three age groups of $0-4,5-9$ and $10-14$ years. However, the two oldest 5 -year age groups became close to each other, and in females the incidence trends for 5-9 year old and 10-14 year old were superimposed since 1973 . These results were almost identical with the findings from Sweden [11].

The incidence of childhood Type 1 diabetes in Finland has increased without any doubts since the early 1950's when the first nationwide incidence study was carried out [22]. Nevertheless, it has not been clear whether this was due to a secular increase, a birth cohort effect or a change in age distribution. To investigate this issue properly we applied an age-period-cohort analysis which has not been widely used for childhood Type 1 diabetes, mainly because the standardized incidence estimates have not been available for most populations for a sufficiently long time period. Moreover, in many registries for childhood Type 1 diabetes, the number of cases per year has been too small to detect spurious trends or to provide sufficient power for statistical inferences from the time trends in incidence.

Our present study in Finland covers so far the longest period i. e. 20-years with a large number of cases per year. Roughly, about 200-300 cases per year are needed in. order to establish a statistically significant trend in incidence with about $2 \%$ increase per year. Another important issue for the assessment of incidence trends is the caseascertainment rate which in Finland is high, approaching $100 \%$ [16]. We can argue that the possibility that the false positives or false negatives have influenced the rates, is very small.
According to our results the increase in the incidence of Type 1 diabetes was neither due to a change in the age distribution nor in the age-relation of the incidence among Finnish children during 1965-1984. Since the increase in diabetes risk appears to be real, two aetiologic possibilities need to be explored: genetic or environmental influences.

The major genetic susceptibility to Type 1 diabetes is conferred by genes in the HLA region located on the short arm of the chromosome 6 and genetic differences may account for much of the geographic variation in incidence. However, it is not likely that such a rapid increase observed in Finland over 20 years is mainly due to genetic factors. It is clear from twin studies that less than one-third of the people who are genetically susceptible will develop overt disease [23]. Since the discovery and availability of insulin the survival of Type 1 diabetic patients has gradually improved. With the ever improving survival of diabetic patients, the number of genetically susceptible people has surely increased. However, if this were the main reason for the increase in incidence the birth cohort effect should be more pronounced.

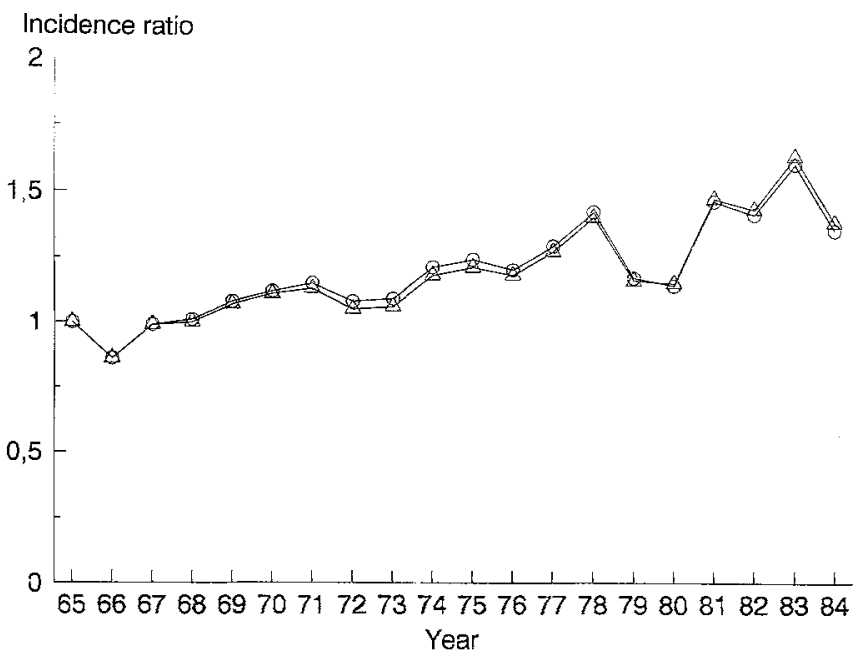

Fig.4. The rate ratios of crude annual incidence rates and the ageand sex-adjusted incidence rates of childhood Type 1 (insulin-dependent) diabetes in Finland during 1966 to 1984, compared with the annual incidence in 1965 . O crude rates, $\triangle$ adjusted rates 
Our results lend strong support to the importance of a common environmental factor (or factors) for the high risk of Type 1 diabetes and for the steep increase in incidence. First, the increase was proportionally similar in different age groups. Secondly, the increase did not completely follow a linear pattern, but the data are suggestive of "epidemic" peaks. Thirdly, our results are very similar to those recently reported from Sweden where the increase in incidence during the ten year period 1978-1987 was about $25 \%$ [11].

A long latency period from the initial exposure to an environmental triggering factor to overt diabetes has been demonstrated [24]. Such an exposure could possibly occur already in utero [25]. Although we did not reveal any significant birth cohort effect, our results do not exclude the hypothesis of in utero exposure. Neither do they support the view that certain rather abrupt environmental changes such as the start of rubella vaccination of young women in the 1970 's or epidemics of common virus infections could have caused the increase in incidence.

Some investigators have proposed that the fall in the duration of breast feeding could be associated with the increase in the risk of Type 1 diabetes [26]. The Finnish data do not confirm this hypothesis, because the duration of breast feeding has steeply increased among the Finnish mothers since the early 1970 's $[27,28]$. It is, however, possible that the protective effect of breast feeding is outweighed by other factors. For instance, the use of cow milk formulas may be one of them [29], and infants often start to receive such formulas while still being breast fed.

The overall incidence in boys was significantly (about $10 \%$ ) higher than in girls. The reason for this is unknown. A male excess has also been reported from some other populations, especially where the incidence of Type 1 diabetes is high, whereas in low incidence populations a slight female excess is often found $[3,4]$. The age-relation of the risk of Type 1 diabetes was different between boys and girls. The male excess in our data was entirely due to the higher incidence in boys than in girls before the age of 3 years and in particular, after the age of 11 years.

It was interesting to note that the peak in the year 1983 was not only observed in Finland, but also in Sweden [11], Poland [30] and the Allegheny county, Pennsylvania, USA [10]. Although in some populations the peak was not very prominent, its consistency across the countries may carry some important message about the environmental aetiology of childhood Type 1 diabetes. In Finland, it has been speculated that a mumps infection epidemic may have contributed to the increasing incidence of Type 1 diabetes in the early 1980's [31]. Viruses have also been speculated to be involved in the incidence peaks observed for instance in Poland [32] and Sweden [11].

Time trend analyses are needed for a better understanding of the aetiology of Type 1 diabetes. Unfortunately, data are presently only available for a few populations, but in the future through the WHO DIAMOND (DIAbetes MONDiale) study standardized incidence trends will be established in a large number of countries in different parts of the world [33].
Acknowledgements. This study was carried out with support of grants from the National Institutes of Health (DK 37957, DK 35905), Sigrid Juselius Foundation, the Association of Finnish life insurance companies and the Nordisk Insulinfond.

\section{References}

1. LaPorte RE, Tajima N, Åkerblom HK et al. (1985) Geographic differences in the risk of insulin-dependent diabetes mellitus: the importance of registries. Diabetes Care 8 [Suppl 1]: 101-107

2. Tajima N, LaPorte RE, Hibi I, Kitagawa T, Fujita $H$, Drash AL (1985) A comparison of the epidemiology of youth-onset insulindependent diabetes mellitus between Japan and the United States (Allegheny County, Pennsylvania). Diabetes Care 8 [Suppl 1]: 17-23

3. Diabetes Epidemiology Research International Group (1988) Geographic patterns of childhood insulin-dependent diabetes mellitus. Diabetes 37: 1113-1119

4. Rewers M, LaPorte RE, King HOM, Tuomilehto J (1988) Insulin-dependent diabetes mellitus in childhood: international patterns and trends. World Health Stat Q 41:179-189

5. North AF, Gorwith K, Sultz HA (1977) A secular increase in the incidence of juvenile diabetes mellitus. J Pediatr 91: 706-710

6. Hägglöf B, Holmgren G, Wall S (1982) Incidence of insulin-dependent diabetes mellitus among children in a North-Swedish population 1938-1977. Hum Hered 32: 408-417

7. Pattersson CC, Thorogood M, Smith PG, Heasman MA, et al. (1983) Epidemiology of Type 1 (insulin-dependent) diabetes in Scotland 1968-1976: evidence of an increasing incidence. Diabetologia 24: $238-243$

8. Siemiatycki J, Colle E, Aubert D, Campbell S, Belmonte M (1986) The distribution of type I (insulin-dependent) diabetes mellitus by age, sex, secular trend, seasonality, time clusters, and space-time clusters: evidence from Montreal, 1971-1983. Am J Epidemiol 124: 545-560

9. Reunanen A, Åkerblom HK, Tuomilehto J (1988) High incidence of insulin-dependent diabetes mellitus (IDDM) in children in Finland. Arctic Med Res 47 [Suppl 1]: 535-539

10. Rewers M, Stone RA, LaPorte RE, Drash AL, Becker DJ, Walczak M, Kuller LH (1989) Poisson regression modelling of temporal variation in incidence of childhood insulin-dependent diabetes mellitus in Allegheny County, Pennsylvania and Wielkopolska, Poland, 1970-1985. Am J Epidemiol 129: 569-581

11. Nyström L, Dahlquist G, Rewers M, Wall S (1990) The Swedish childhood diabetes study. An analysis of the temporal variation in diabetes incidence 1978-1987. Int J Epidemiol 19: 141-146

12. Holford TR (1983) The estimation of age, period and cohort effects for vital rates. Biometrics 39:311-324

13. Kupper LL, Janis JM, Karmous A et al. (1985) Statistical ageperiod-cohort analysis: a review and critique. $J$ Chron Dis 38 : $811-830$

14. Osmond C, Gardner MJ (1982) Age, period and cohort models applied to cancer mortality rates. Stat Med 1:245-259

15. O'Malley PM, Bachman JG, Johnston LD (1988) Period, age, and cohort effects on substance use among young Americans: a decade of change, 1976-1986. Am J Public Health 78: 1315-1321

16. Reunanen A, Äkerblom HK, Käär ML (1982) Prevalence and ten-year (1970-1979) incidence of insulin-dependent diabetes in children and adolescents in Finland. Acta Paediatr Scand 71: 893-899

17. Åkerblom HK, Reunanen A (1985) The epidemiology of insulindependent diabetes mellitus (IDDM) in Finland and in Northern Europe. Diabetes Care 8 [Suppl 1]: 10-16

18. Bureau of the Census (1984) Intercensal estimates of the population of counties by age, sex and race: 1970-1980. Bureau of the Census, Washington (publication no. HSD-377)

19. Lilienfeld AM, Lilienfeld DE (1980) Foundations of epidemiology. Oxford University Press, New York 
20. Baker RJ, Nelder JA (1978) GLIM (Generalized Linear Interactive Modelling) release 3.77. Royal Statistical Society, Oxford

21. McCullagh P, Nelder JA (1983) Generalized linear models. Chapman and Hall, London

22. Somersalo O (1955) Studies of childhood diabetes. I. Incidence in Finland. Ann Paediatr Fenn 1:239-249

23. Barnett AH, Eff C, Leslie RDG, Pyke DA (1981) Diabetes in identical twins. Diabetologia 20: 87-93

24. Gorsuch AN, Spencer KM, Lister J et al. (1981) The natural history of Type I (insulin-dependent) diabetes mellitus: evidence for a long prediabetic period. Lancet II: 1363-1365

25. Helgason T, Jonasson MR (1981) Evidence for a food additive as a cause of ketosis prone diabetes. Lancet II: 716-720

26. Borch-Johnsen K, Mandrup-Poulsen T, Zachau-Christiansen B, Joner G, Christy M, Kastrup K, Nerup J (1984) Relation between breast feeding and incidence rates of insulin-dependent diabetes mellitus. A hypothesis. Lancet II: 1083-1086

27. Verkasalo M (1980) Recent trends in breast feeding in Southern Finland. Acta Paediatr Scand 68: 277-279

28. Verronen P (1988) Promotion of breast feeding at a maternity unit and well-baby clinics. Academic Dissertation. Acta Universitäts Tamperensis. Ser A 253

29. Rewers M, LaPorte RE, Walczak M, Dmochowski K, Bogaczynska E (1987) Apparent epidemic of insulin-dependent diabetes mellitus in midwestern Poland. Diabetes 36: 106-113
30. Elliot RB, Martin JM (1984) Dietary protein: a trigger of insulin dependent diabetes in the BB rat? Diabetologia 24:297-299

31. Hyöty H, Leinikki P, Reunanen A et al. (1988) Mumps infections in the etiology of Type 1 (insulin-dependent) diabetes. Diabetes Res 9: 111-116

32. Rewers M, LaPorte RE, Walczak M, Dmochowski K, Bogaczynska E (1987) Apparent epidemic of insulin-dependent diabetes mellitus in midwestern Poland. Diabetes 36: 106-113

33. WHO DIAMOND Project Group (1990) The WHO Multinational Project for Childhood Diabetes. Diamond: Diabetes mondiale. Diabetes Care 13: 1062-1068

Received: 6 August 1990

and in revised form: 16 January 1991

Dr. J. Tuomilehto

Department of Epidemiology

National Public Health Institute

Elimäenkatu 25A, 6th Floor

SF-00510 Helsinki

Finland

\section{Announcement}

The 4th International Immunology and Diabetes Workshop (IDW), the 3rd International Diabetes Immunotherapy Group (IDIG) Symposium and the 1st Islet Cell Antibody Register Users Study (ICARUS) Workshop

These workshops and the symposium will be held from November 14-17, 1991 in Nagasaki City, Japan. Deadline for submission of Abstracts: June 15, 1991. For further information please contact: 11 th IDW Headquarters, Dr. S. Nagataki, The First Department of Internal Medicine, Nagasaki University School of Medicine, Nagasaki 852, Japan, Fax 81-958-43-0255.

\section{Erratum}

Diabetologia, Volume 33, Number 9, September 1990, pp. 542-548

N.J.Morrish et al.: A prospective study of mortality among middleaged diabetic patients (the London cohort of the WHO Multinational Study of Vascular Disease in Diabetics) II: associated risk factors

In the summary the estimate of relative risk for cardiovascular disease in IDDM is quoted as 18.6; the actual figure as stated in Table 8 is 4.6 . 